\title{
Anterograde versus retrograde techniques: Can we use surgical margin status as a quality indicator?
}

\author{
D. Robert Siemens, MD, FRCSC
}

See related article on page 192.

$\longrightarrow$ uality of care research evaluates the "degree to which health services for individuals and populations increase the likelihood of desired health outcomes and are consistent with current professional knowledge. ${ }^{1}$ Efforts to better understand, measure and influence surgical quality, however, have often been impeded by a lack of reliable and valid measurements and a failure to control for patient characteristics. ${ }^{2}$ Expert panels organized by the RAND group and by Cancer Care Ontario have recommended several different quality indicators for prostate cancer surgery. 3,4 However, there is very little evidence of the feasibility, reliability and validity of many of the proposed indicators, undermining their application to the quality-ofcare process.

Surgical margin status as an indicator of quality for prostate cancer care is an interesting example of this dilemma. The variation in rate of margin positivity in different surgical series is remarkable, most obviously if they reflect surgeon experience from a high volume centre of excellence or from a population-based study. ${ }^{5}$ Furthermore, using margin status as an indicator of quality is confusing as it is often as much a reflection of case mix or pathological expertise as it is surgical technique. Most authors generally agree that a positive margin has a negative impact on disease outcomes after radical prostatectomy. The strength of its prognostic value, however, may vary depending on postoperative risk status and is uncommonly demonstrated to be predictive of clinical progression, cancer-specific or overall mortality. 6,7

With that being said, every surgeon wants to be able to tell the patient postoperatively that "we got it all." The psychological burden of a positive margin, let alone the addition of side effects associated with adjuvant or salvage therapy, should assure our commitment to improving this quality indicator. Sciarra and colleagues, in this issue of CUAJ, report the effect of surgical technique on positive margins in a randomized trial between an open anterograde approach compared to a more standard retrograde open radical prostatectomy. ${ }^{8}$ In this study the authors describe a possible benefit from the anterograde dissection, starting at the bladder neck and dissecting the lateral and apical aspects of the prostate with a wider surgical view, leading to a beneficial effect on margin status although with greater blood loss. The authors demonstrate an overall low margin positive rate assessed by whole mount sections at pathology, with $14 \%$ positive in the anterograde group versus $18 \%$ with the routinely performed open procedure.

A more rigid statistical review of the data might moderate the authors' conclusions that the anterograde dissection is superior given the apparent lack of allowance for repeated measures in the analysis as well as the omission of surgical technique in the multivariate analysis. As the absolute difference in margin rate was only 4 cases between the two groups, it is difficult to validate technique as an independent factor without controlling for the other obvious factors such as stage, grade and PSA. The apparent benefit of margin status with the anterograde approach appeared to be only in those with pT2 tumours (with numerically more positive margins with the anterograde technique in those with capsular penetration). The eventual effect of technique on biochemical recurrence would therefore be important although the paper unfortunately does not describe these outcomes (follow-up is limited). The authors have significant experience with the anterograde approach and it would be of interest to determine if surgeon volume of the two techniques prior to the trial had any effect on outcome. Finally, the rates of incontinence and erectile dysfunction seem inconsistent with other studies using strict and validated measures although no effect of surgical technique is apparent.

Despite these caveats, the authors should be congratulated in completing a randomized study of surgical technique in prostate cancer, an achievement that readers will recognize as noteworthy. This study is relevant in the contemporary debate of minimally invasive (anterograde) versus open (retrograde) approaches to the prostate. Consistent with most other non-randomized series this report appears to confirm that the approach to radical prostatectomy may be less important in margin outcomes as compared to surgeon experience and decision-making as well as the cancer biology. Those surgeons with significant experience with an open retrograde approach need not switch to an 
anterograde approach based on this data. However, this should not diminish the importance of continually striving for technical proficiency and the ongoing critical practice review that is required to attain optimal quality of care for our patients.

Associate Professor of Urology, Department of Urology, Queen's University, Kingston, ON

Competing interests: None declared.

This paper has been peer-reviewed.

\section{References}

1. Spencer BA, Steinberg M, Malin J, et al. Quality-of-care indicators for early-stage prostate cancer. J Clin Oncol 2003;21:1928-36.

2. Miller DC, Montie JE, Wei JT. Measuring the quality of care for localized prostate cancer. J Urol 2005; 174:425-31.

3. Gagliardi AR, Fleshner $\mathrm{N}$, Langer $\mathrm{B}$, et al. Development of prostate cancer quality indicators: a modified Delphi approach. Can J Urol 2005;12:2808-15.

4. Litwin MS, Steinberg M, Malin J, et al. Prostate Cancer Patient Outcomes and Choice of Providers: Development of an Infrastructure for Quality Assessment. Santa Monica, CA: RAND; 2000.

5. Chan $E 0$, Groome PA, Siemens DR. Validation of quality indicators for radical prostatectomy. Int I Cancer 2008; 123:2651-7.

6. Alkhateeb S, Alibhai S, Fleshner N, et al. Impact of Positive Surgical Margins After Radical Prostatectomy Differs by Disease Risk Group. J Urol 2010;183:145-50.

7. Vis AN, Schroder FH, van der Kwast TH. The actual value of the surgical margin status as a predictor of disease progression in men with early prostate cancer. Eur Urol 2006;50:258-65.

8. Sciarra A, Cristini $C$, Von Heland $M$, et al. Randomized trial comparing an anterograde versus a retrograde approach to open radical prostatectomy: results in terms of positive margin rate. Can Urol Assoc J 2010;4(3):192-8.

Correspondence: Dr. D. Robert Siemens, Department of Urology, Kingston General Hospital, 76 Stuart St., Kingston, 0N; fax: 613-545-1970; siemensı@kgh.kari.net 